Western North American Naturalist 68(3), (C 2008, pp. 382-389

\title{
USE OF A MINE BY EASTERN PIPISTRELLES (PERIMYOTIS SUBFLAVUS) IN EAST CENTRAL NEBRASKA
}

\author{
Jason P. Damm ${ }^{1}$ and Keith Geluso ${ }^{1,2}$
}

\begin{abstract}
The eastern pipistrelle (Perimyotis subflavus) is relatively common and widespread throughout the eastern United States. In recent decades, the distribution of $P$. subflavus has expanded westward across the Great Plains, and little information exists on its natural history in this region. In east central Nebraska, we monitored the use of a mine by eastern pipistrelles for $>1$ year. A few males occupied the roost in summer, but during the period of hibernation (late September-early May), the mine was used by at least 30 individuals composed of both sexes. Most individuals first entered the mine during late September through mid-October and exited by mid-May, with numbers of individuals fluctuating throughout winter. In winter, most individuals roosted along outer passageways of the mine, but in other seasons individuals were scattered throughout the mine. Females had significantly greater body masses than males upon entering the mine in autumn and before exiting the mine in spring. Both sexes had significantly heavier body masses in autumn than in spring. Overall, $55 \%$ of individuals marked in spring returned in autumn. Males had a higher return rate (69\%) than females $(46 \%)$ over a single summer. Many aspects of the natural history of $P$. subflavus in Nebraska are similar to those reported from eastern but not from southern parts of its distribution.
\end{abstract}

Key words: eastern pipistrelles, Perimyotis subflavus, Pipistrellus subflavus, Nebraska, mines, seasonality, hibernacula, body masses, site fidelity.

The eastern pipistrelle (Perimyotis subflavus) is relatively common and occurs in the United States from the Atlantic coast westward across the Great Plains to Wyoming, Colorado, New Mexico, and Texas (Geluso et al. 2005). This species also occurs in southeastern Canada, eastern Mexico, Honduras, and Guatemala (Hall 1981, Fujita and Kunz 1984). In recent decades, the distribution of $P$. subflavus has expanded westward across the Great Plains (Geluso et al. 2005). This westward expansion is attributed to increases in trees along rivers and increases in winter roosting sites, such as mines and other human-made structures (Benedict et al. 2000, Sparks and Choate 2000, Geluso et al. 2005). During warmer months, $P$. subflavus roosts in trees, but it also regularly occupies buildings (Fujita and Kunz 1984). In winter, $P$. subflavus typically hibernates in caves, mines, and other human-made structures (Fujita and Kunz 1984, Kurta and Teramino 1994, Walker et al. 1996, Briggler and Prather 2003).

Although P. subflavus is relatively common in eastern parts of its range, little is known about many aspects of its natural history (Jones et al. 1983, Briggler and Prather 2003). In western parts of its range, even less infor- mation is known because of few records and its recent arrival. In Nebraska, P. subflavus originally was known only from limestone quarries in extreme eastern parts of the state in winter (Czaplewski et al. 1979). Recently, some additional captures have been reported in summer from northern and central Nebraska (Benedict 2004) and from extreme eastern Nebraska (Geluso et al. 2004).

Our study examined seasonal use of a mine by $P$. subflavus for $>1$ year near the northwestern edge of its distribution. This site had relatively few passageways; all passageways were low in height with all bats visually exposed due to the lack of deep cracks and crevices. For this study, we examined the following questions: (1) Does P. subflavus occupy the mine throughout the year? (2) Are both sexes present in the mine and in what ratio do they occur? (3) Do roosting sites in the mine vary seasonally? (4) Do sexes differ in body mass throughout the year? (5) Do bats return to this hibernaculum after summer? (6) Are aspects of its natural history in east central Nebraska similar to those in other parts of its distribution?

In Nebraska and throughout the Great Plains, mines are uncommon, and many have

${ }^{1}$ Department of Biology, University of Nebraska at Kearney, Kearney, NE 68849.

${ }^{2}$ Corresponding author. E-mail: gelusok1@unk.edu 
been closed or modified. The site of our study has many anthropogenic disturbances throughout the year; and without a detailed examination of the species present, timing of use, and reasons why bats use this mine, appropriate and relevant management concerns could not be addressed. Our research interests were sparked, in part, by the paucity of information concerning the natural history of hibernating bats in Nebraska during the period of hibernation.

\section{Study AREA}

We conducted this study at the Happy Jack Chalk Mine, 1.2 mi. S, 1.0 mi. W Scotia, Greeley County, Nebraska $\left(41^{\circ} 26^{\prime} 32.9^{\prime \prime} \mathrm{N}, 98^{\circ}\right.$ $42^{\prime} 31.8^{\prime \prime} \mathrm{W}$, North American Datum 1983). The mine is located in east central Nebraska and was excavated from the south side of Happy Jack Peak (elevation $610 \mathrm{~m}$ ). This deposit, a late Miocene lacustrine calcareous diatomite, has been referred to as "chalk" because of its consistency, whiteness, and high lime content (Joeckel et al. 2003). Vegetation surrounding the bottom of the hill is composed primarily of eastern cottonwoods (Populus deltoides), eastern redcedars (Juniperus virginiana), and bur oaks (Quercus macrocarpa). Higher areas on the hill are dominated by mixed grasses, shrubs, and a few scattered J. virginiana. To the north and west, the area generally consists of rolling hills of sand dominated by mixed grasses. About $70 \mathrm{~m}$ east of the mine, the North Loup River runs from north to south and contains large patches of riparian forest. Farther to the east, the landscape consists mainly of agricultural fields and rolling hills used as pasture.

To access a honeycomb of horizontal passageways, bats entered the mine through 2 openings about $48 \mathrm{~m}$ apart on the south side of the hill. Each opening consisted of a relatively narrow, horizontal space above a solid wooden doorway. The opening above the westernmost door ranged from 5 to $15 \mathrm{~cm}$ in height and was $190 \mathrm{~cm}$ in width, whereas the easternmost opening was $15 \mathrm{~cm}$ in height and $210 \mathrm{~cm}$ in width. Air movement was minimal in the mine because both openings were on the same aspect of the hill and at the same elevation. Throughout the year, ambient temperature and relative humidity remained fairly constant in the rear of the mine, $10-13^{\circ} \mathrm{C}$ and $90-95 \%$, respectively. Most passageways ranged in height from 1.8 to $2.0 \mathrm{~m}$. The greatest length of the mine was about $140 \mathrm{~m}$, and its greatest width was about $100 \mathrm{~m}$. A layout of passageways is shown in Joeckel et al. (2003). The 2 adits that began at doorways were lined with redcedar timbers, and some additional timbers were used in other parts of the mine in the larger spacious passageways.

The hill was first mined in 1877 , and the mine remained active until 1945 (Joeckel et al. 2003). The mine remained closed until 1969, when it was opened for tourism for a brief period (Anonymous 2005). In 1998, the mine was reopened for tourism, and public tours generally are conducted from late May (Memorial Day) to early September (Labor Day). During open hours, front passages are lit with floodlights, and large fans are used to dry floors throughout the year. In October, the mine is used as a "haunted house" (i.e., a public entertainment venue). The mine also is occasionally entered during the colder months (J.P. Damm personal observation). As for bats, it is unclear how long they have occupied the mine, but a local resident (Thurman Garner, personal communication) indicated that his earliest recollection of them was from the 1940s during summers when doors were not present on the 2 openings.

\section{Methods}

From 25 June to 23 July 2005 , we monitored bats in the mine by placing a doubleframed harp trap in front of 1 opening on 6 occasions. From September 2005 to February 2006, we continued to monitor bats about every $4-8$ weeks by entering the mine during daylight hours and surveying with flashlights. During those months, we counted individuals and marked each roost location on a map of the internal workings of the mine. We did not handle bats, and surveys were conducted as quickly as possible to minimize disturbance during hibernation (Speakman et al. 1991, but see Thomas 1995).

On 8 April 2006, we captured individuals by hand and determined sex, body mass, and forearm length of members of this colony before their seasonal movements from the mine. In addition, we permanently marked each bat with a uniquely marked tag (passive integrated transponder = PIT tag; Biomark, Inc., Boise, ID, www.biomark.com). Sterile PIT tags were injected subcutaneously between scapulae with 


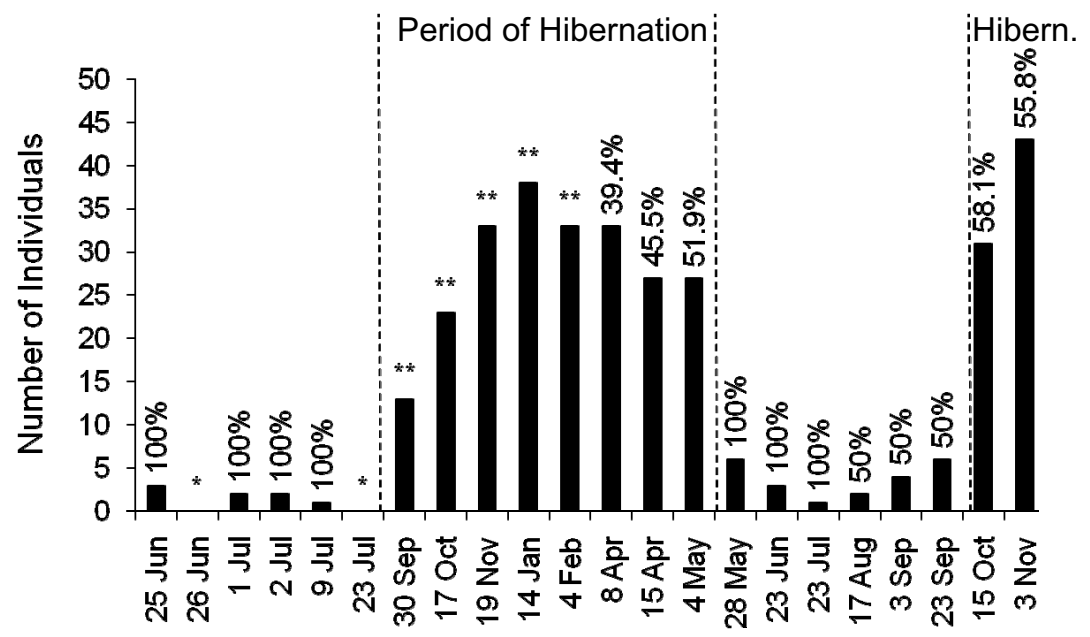

Fig. 1. Numbers of eastern pipistrelles (Perimyotis subflavus) occupying the Happy Jack Chalk Mine, Greeley County, Nebraska, from 25 June 2005 to 3 November 2006. Surveys from 25 June to 23 July 2005 represent numbers of bats captured in a harp trap at 1 entrance of the mine, whereas other dates represent numbers of bats counted by visual inspection in passageways. A single asterisk (*) denotes no capture of bats in a harp trap. Percentage of males during each visit, if known, is listed above each bar. If percentage of males was unknown, a double asterisk $(* *)$ is listed above the bar.

sterile 12-gauge hypodermic needles and syringes.

From mid-April to November 2006, we continued to count bats and monitor locations of roosting sites. We also determined whether each bat was tagged by scanning them with a handheld reader (Pocket Reader EX; Biomark, Inc., Boise, ID). If we detected unmarked individuals, we processed and tagged them as described above, except we did not tag them on 15 April or on 3 November. On 15 October and 3 November 2006, we handled both marked and unmarked bats once to determine body mass near the start of hibernation.

We entered the mine multiple times during the period of hibernation, and we acknowledge that this procedure does not adhere to guidelines for conducting research in hibernacula, as proposed by the American Society of Mammalogists (1992). Instead we opted to understand use of the mine by $P$. subflavus, especially the timing of when individuals enter and exit this hibernaculum, to educate and hopefully reduce future anthropogenic activities in the mine while bats are present and hibernating.

We analyzed data on body masses of bats with Student's $t$ tests and paired $t$ tests using SAS/STAT software, Version 9.1, of the SAS System for Windows (SAS Institute, Inc., Cary, $\mathrm{NC}$ ). Length of forearm of 1 male was removed from 1 of our analyses because it was an outlier and measured $27.0 \mathrm{~mm}$; we suspect the measurement resulted from investigator error. Two males were kept as voucher specimens and deposited in natural history collections in the Division of Zoology, University of Nebraska State Museum (UNSM), University of Nebraska at Lincoln (UNSM 28931 and 28932).

\section{RESUlts}

During our study, P. subflavus was the only species of bat captured or observed in the mine, and numbers of individuals ranged from 0 to 43 (Fig. 1). During both summers (JuneAugust), mostly males occupied the mine (Fig. 1). In summer 2005 , we captured 8 males in harp traps. In summer 2006, we observed 4 different males, and 2 were observed on more than 1 visit. In 2006, the 1st observation of a female (postlactating) returning to the mine was on 17 August. We did not determine the 1st arrival of females in 2005.

From November to April, all individuals appeared torpid. In May, September, and October we observed alert and torpid individuals. In both years, the greatest influx of bats of both sexes occurred from late September to mid-October (Fig. 1). During winter, numbers of both sexes were greatest. In winter of 2005/2006, the greatest number of $P$. subflavus 
TABLE 1. Body masses ( $\mathrm{g}$ ) of eastern pipistrelles (Perimyotis subflavus) in spring and autumn from the Happy Jack Chalk Mine, Greeley County, in east central Nebraska. Body masses were measured near the end ( 8 April and 4 May) and near the start (15 October and 3 November) of hibernation in 2006. Means represent data from tagged and untagged individuals.

\begin{tabular}{lccccccc}
\hline & \multicolumn{3}{c}{ Spring } & & \multicolumn{3}{c}{ Autumn } \\
\cline { 2 - 3 } Sex & Mean $\pm s$ & Range & $n$ & & Mean $\pm s$ & Range & $n$ \\
\hline Females & $6.8 \pm 0.68$ & $5.5-8.1$ & 24 & & $7.7 \pm 0.57$ & $6.75-8.65$ & 18 \\
Males & $5.5 \pm 0.58$ & $4.5-6.7$ & 16 & & $6.9 \pm 0.64$ & $5.55-7.75$ & 22 \\
\hline
\end{tabular}

occurred in mid-January with 39 individuals, but numbers fluctuated at lower levels through April (Fig. 1). Most bats exited the mine in May, and only a few males remained at the end of the month. In late May 2006, we captured 2 males previously not tagged.

Sex ratios, based on all tagged bats (i.e., from 8 April to 15 October), were about equal (31 females and 28 males). On 8 April 2006, we tagged 20 females and 13 males. On 4 May 2006, we observed 13 females and 14 males (4 females and 3 males were untagged). In summer 2006, all observations were males $(n=6)$, except for the postlactating female captured in August. On 15 October, we observed 13 females and 18 males $(5$ females and 9 males were untagged). On 3 November 2006, we observed 19 females and 24 males ( 5 females and 7 males were untagged).

\section{Roosting Sites in Mine}

From 19 November 2005 to 8 April 2006, bats were observed in the greatest abundance (90\%) along outer passageways of the mine. Based on data from 8 April, these individuals included both sexes. On other dates, bats roosted in outer and central passageways throughout the entire mine. In all seasons, bats roosted solitarily, and with 1 exception, bats were not observed to be closer than about $1 \mathrm{~m}$ from each other. On 1 occasion, 2 males were directly adjacent to each other, about 1 $\mathrm{cm}$ apart. Bats roosted on ceilings and on vertical walls. On walls, bats were always $>0.5 \mathrm{~m}$ from the floor. Bats also were observed facing outward in shallow, circular drill holes in the ceiling; holes ranged from 3 to $7 \mathrm{~cm}$ in diameter. No bats were observed roosting on vertical or horizontal redcedar timbers.

\section{Body Masses}

At both the end and beginning of hibernation, females were significantly heavier than males $(t=6.61$, df $=38$ and $t=4.16$, df $=38$, respectively; $P<0.001$ for both; Table 1 ). Lengths of forearms were significantly longer for females $(34.6 \pm 0.8 \mathrm{~mm}[\bar{x} \pm s]$, range 33.0-36.0 mm, $n=31)$ than for males $(34.0 \pm$ $1.0 \mathrm{~mm}$, range $31.9-35.9 \mathrm{~mm}, n=27 ; t=2.8$, $\mathrm{df}=56, P=0.007$ ). For marked individuals, body masses of both sexes were significantly heavier in autumn than in spring (females: $t=$ -4.8 , df $=10, P<0.001$; males: $t=-12.44$, df $=10, P<0.001)$. Mean body mass was $0.9 \pm$ $0.59 \mathrm{~g}$ heavier (range 0.00-1.80 g) in adult females and $1.2 \pm 0.33 \mathrm{~g}$ heavier (range 0.75$1.80 \mathrm{~g})$ in adult males.

\section{Site Fidelity}

On 15 October and 3 November 2006, 55\% $(22 / 40)$ of individuals tagged the previous spring were observed in the mine. Males had a $69 \%$ return rate $(11 / 16)$, and females had a $46 \%$ return rate $(11 / 24)$. After originally tagging 33 bats on 8 April, we observed only 22 $(67 \%)$ of those individuals on 15 April; an additional 5 untagged bats were observed and not tagged on this date. On 4 May, we observed 20 of the $33(61 \%)$ originally tagged bats, including 6 individuals tagged on 8 April not observed on 15 April.

\section{Discussion}

Based on observations of $P$. subflavus in the Happy Jack Chalk Mine in east central Nebraska, the period of hibernation for this species appears to be from late September to early May. During this period, all (NovemberApril) or some (September, October, and May) individuals were in a state of torpor. Many individuals left the mine in May, presumably to establish summer roosts, and returned in September and October. From June to August, most bats (especially females) were absent from the mine (Fig. 1).

Eastern pipistrelles were the only species of bat observed in the mine. Absence of other 
species that hibernate in limestone quarries farther east in Nebraska (i.e., Myotis lucifugus, M. septentrionalis, and Eptesicus fuscus; Jones 1964) suggests that those species do not occur in the area or perhaps conditions in the mine are not conducive for hibernation. McNab (1974) determined that hibernating bats appear to select roost temperatures inversely related to body mass. That is, smaller species, such as P. subflavus, tend to hibernate in the warmest regions of hibernacula, whereas larger species, such as E. fuscus, select the coldest temperatures, usually located near entrances of caves and mines. Neither M. lucifugus nor M. septentrionalis are known from this part of Nebraska (Benedict 2004), but we have captured E. fuscus in Howard County, the next county to the south (J.P. Damm and K. Geluso unpublished data). Ambient temperatures, even near entrances of the mine, might be too warm for $E$. fuscus to successfully overwinter. Big brown bats require temperatures $<7^{\circ} \mathrm{C}$ for hibernation (McNab 1974).

\section{Seasonal Use}

In the mine, we observed the greatest number of $P$. subflavus during the period of hibernation, and in summer we generally observed a few males. In Arkansas (Briggler and Prather 2003) and Indiana (Whitaker and Rissler 1992a, 1992b), P. subflavus also hibernates in caves and mines. In Arkansas, $<10$ individuals were observed in caves in summer, but during hibernation, $>160$ were observed in 54 caves (Briggler and Prather 2003). In our study, 2 males tagged in April periodically occupied the mine in summer, but most males exited the mine by mid-May along with females. In Indiana, Whitaker and Rissler (1992a) also showed that most activity at a mine entrance in summer involved males.

Duration of hibernation for $P$. subflavus is long compared to other hibernating species in the eastern United States (LaVal and LaVal 1980). For P. subflavus in Nebraska, this period generally was from late September to early May for many individuals (Fig. 1). The period of hibernation in Nebraska was most similar to P. subflavus in eastern parts of its range (LaVal and LaVal 1980, Jones et al. 1983, Whitaker and Rissler 1992a, Whitaker 1998) rather than in southern parts of its range (e.g., OctoberMarch in Texas; Sandel et al. 2001). Our earliest documented arrival of a female to the mine was on 17 August 2006, which is similar to dates reported by studies in eastern parts of its distribution (LaVal and LaVal 1980, Whitaker and Rissler 1992a).

In eastern parts of the range of P. subflavus, summer maternity roosts of females generally are located in buildings and trees (Whitaker 1998, Veilleux et al. 2003, Veilleux and Veilleux 2004). However, little is known about the roosting sites of males in summer (Kunz 1999). In Nebraska, the only known summer roosts include a mine (this study), limestone quarries in Cass and Sarpy counties (Czaplewski et al. 1979), and a garage in Cass County (Geluso et al. 2004).

On 14 January 2006, we counted 39 individuals in the mine, but fewer bats $(\leq 33)$ were observed through May. This decrease suggests that individuals died or exited the mine to use other types of winter roosts, possibly culverts and sewers (Goehring 1954, Walker et al. 1996). The decrease of 6 bats from 8 April to 15 April likely was associated with our handling and tagging of bats. To our knowledge, no other mines exist in the area, and the closest quarries exist $200 \mathrm{~km}$ to the east in Cass and Sarpy counties. We suspect most individuals exited the mine for other roosts because we never discovered a dead bat in the mine, and carnivores were limited from entering the mine. Some individuals may have lost tags shortly after injection. In April 2006 we observed that 6 individuals absent on our following visit were observed again in later surveys. These observations, plus the appearance of unmarked individuals in mid-April and early May, suggest that other nearby winter roosts are used in the region.

\section{Roosting Sites}

In winter, a majority of roosting sites $(90 \%)$ were along the outer passageways of the mine, but on other dates, roosting sites generally were scattered throughout the entire mine. During cold months, P. subflavus commonly roosts deep in hibernacula, where temperatures are more stable and generally warmer (Rabinowitz 1981, Fujita and Kunz 1984, Briggler and Prather 2003). By selecting stable roosting sites, individuals do not arouse and expend energy as they would near entrances where fluctuations in temperature are greater (Rabinowitz 1981).

While many bats were entering the mine to hibernate, it was used as a "haunted house" on 
weekends in October. Exhibits in the haunted house were erected primarily in front regions of the mine near and between the openings, blocking corridors to openings. In winter 2005/2006, exhibits were not removed until May, and bats generally were absent from the front of the mine. In winter 2006/2007, exhibits were removed in November, as we suggested to management, and bats were observed along front areas of the mine (J.P. Damm unpublished data). We suspect that nontactile stimuli generated by human activity for this event, such as noise, lights, and distortions to temperatures and air movement, also resulted in displacement of bats from front parts of the mine (see Thomas 1995).

As winter progressed, we observed conspicuous formation of dewdrops on many individuals. Unlike Myotis that arouse frequently in winter, P. subflavus moves little during hibernation (Davis 1964, Whitaker and Rissler 1992a, 1992b), thus, droplets of water accumulate on them (Whitaker and Rissler 1992a). On several occasions in late winter, we noted individuals with wet, matted fur or with no dew. We observed that some individuals moved within the mine and suspect they even exited the mine in winter, especially as spring approached (Whitaker and Rissler 1992b). Individuals likely move within the mine to select specific ambient conditions (Fujita and Kunz 1984).

As reported in eastern parts of its range (Jones and Suttkus 1973, Fujita and Kunz 1984, Briggler and Prather 2003), we also observed the solitary roosting behavior of $P$. subflavus in Nebraska. Occasionally, we observed bats within $3 \mathrm{~m}$ of each other, and on 1 occasion, 2 males were about $1 \mathrm{~cm}$ apart. In Texas, clusters of 2-3 individuals roosting in highway culverts have been observed on a number of occasions, and in this situation roost temperatures fluctuated greatly (Sandel et al. 2001).

\section{Body Masses}

A priori differences in body masses were expected between sexes (Myers 1978, Williams and Findley 1979). Deposits of subcutaneous fat generally were greater in autumn than in late spring. This increase in fat is requisite for survival during hibernation (McNab 1974, Speakman and Thomas 2003). In our study, body masses of P. subflavus in April were greater than those reported in Indiana from
March to May (Lindsay 1956) and in Texas (Schmidly 1991). Quantity of fat deposition within a species generally is related to length of hibernation (McNab 1974).

\section{Site Fidelity}

Eastern pipistrelles are known to return to the same hibernacula year after year throughout the species' distribution (Davis 1966, Jones and Pagels 1968, Jones and Suttkus 1973, Sandel et al. 2001). Thus, we expected that some individuals tagged in spring would return in autumn. At our study site, we observed a higher percentage of tagged males (69\%) than tagged females (46\%) returning in autumn. Davis $(1959,1966)$ showed a similar trend in West Virginia. In contrast, higher returns of females than males were reported at sites in Texas and Louisiana (Jones and Pagels 1968, Sandel et al. 2001).

\section{Conclusions}

We examined many aspects of the natural history of $P$. subflavus in the northwestern part of its distribution. Overall, we observed similar behaviors of this species in the Happy Jack Chalk Mine compared to those reported from eastern, but not southern, parts of its distribution. A long-term study at this site would be valuable to examine survival rates and determine whether this colony is stable and always present. Information on summer habits of both sexes in the region would be informative. We suspect that the colony at this mine represents a potential source for the westward expansion of this species. Continued westward movement of eastern pipistrelles in Nebraska is likely to occur, but probably will be limited by availability of suitable roosts, especially winter hibernacula. Farther westward, riparian gallery forests and buildings might provide suitable summer roosts, but the great expanse of the Nebraska Sandhills is largely devoid of natural sites suitable as winter roosts for $P$. subflavus.

Benedict (2004) discussed the importance of mines in eastern Nebraska for hibernating species of bats and proposed that these limited environments should be a priority for conservation in the state. From our observations of when the Happy Jack Chalk Mine is most used by $P$. subflavus, we recommend that entrance by humans should be reduced from late September to early May. Our management 
suggestions already have limited some of the most detrimental activities in the mine. For instance, we suggested removing plastic barriers immediately after use in the "haunted house" so that exit routes to the 2 openings used by bats would be unblocked. We hope management will continue to keep passageways clear for the seasonal movements of bats in and out of the mine. We support positive dialog and interactions between landowners and state officials in order to reach a compromise between using the mine for commercial purposes and as a hibernaculum for wintering bats, and to prevent mines from being sealed to exclude bats.

\section{ACKNOWLEDGMENTS}

We thank the Happy Jack Chalk Mine Association and staff for access to and use of facilities; John Falconer and Diane Holcomb of Sponsored Programs at the University of Nebraska at Kearney for financial assistance in the early stages of this project; Nicholas Czaplewski for technical advice regarding harp traps; Dana Damm for help in the field; and Leslie Carraway, Nicholas Czaplewski, Kenneth Geluso, Joseph Springer, Rick Sherwin, and anonymous reviewers for comments on earlier versions of this manuscript. We also thank Thurman Garner for information about the mine before its reopening in 1998. This study was conducted by the senior author for his undergraduate senior thesis at the University of Nebraska at Kearney (UNK). This project was conducted in accordance with proposals written by Keith Geluso, which were approved by the Institutional Animal Care and Use Committee at UNK and by the Nebraska Game and Parks Commission.

\section{Literature Cited}

American Society of Mammalogists. 1992. Guidelines for the protection of bat roosts. Journal of Mammalogy 73:707-710.

ANONYMOUs. 2005. Happy Jack Chalk Mine: millions of years in the making. Nebraska Travel and Tourism Brochure.

BENEDICT, R.A. 2004. Reproductive activity and distribution of bats in Nebraska. Western North American Naturalist 64:231-248.

Benedict, R.A., H.H. Genoways, and P.W. Freeman. 2000. Shifting distributional patterns of mammals in Nebraska. Transactions of the Nebraska Academy of Sciences 26:55-84.

Briggler, J.T., and J.W. Prather. 2003. Seasonal use and selection of caves by the eastern pipistrelle bat (Pip- istrellus subflavus). American Midland Naturalist 149:406-412.

Czaplewski, N.J., J.P. Farney, J.K. Jones, JR., and J.D. DRUECKER. 1979. Synopsis of bats of Nebraska. Occasional Papers, The Museum, Texas Tech University $61: 1-24$.

DaVIS, W.H. 1959. Disproportionate sex ratios in hibernating bats. Journal of Mammalogy 40:16-19.

. 1964. Winter awakening patterns in the bats Myotis lucifugus and Pipistrellus subflavus. Journal of Mammalogy 45:645-647.

1966. Population dynamics of the bat Pipistrellus subflavus. Journal of Mammalogy 47:383-396.

FujiTa, M.S., AND T.H. KunZ. 1984. Pipistrellus subflavus. Mammalian Species 228:1-6.

Geluso, K., T.R. Mollhagen, J.M. Tigner, and M.A. BOGan. 2005. Westward expansion of the eastern pipistrelle (Pipistrellus subflavus) in the United States, including new records from New Mexico, South Dakota, and Texas. Western North American Naturalist 65:405-409.

Geluso, K.N., R.A. Benedict, AND F.L. Kock. 2004. Seasonal activity and reproduction in bats of east-central Nebraska. Transactions of the Nebraska Academy of Sciences 29:33-44.

Goenring, H.H. 1954. Pipistrellus subflavus obscurus, Myotis keenii, and Eptesicus fuscus hibernating in a storm sewer in central Minnesota. Journal of Mammalogy 35:434-435.

HaLL, E.R. 1981. The mammals of North America. 2nd edition. John Wiley \& Sons, Inc., New York.

Joeckel, R.M., S.T. Tucker, and B.J. Ang Clement. 2003. Lacustrine calcareous diatomite and its mining history in east-central Nebraska. Proceedings of the 39th Forum on the Geology of Industrial Minerals. Nevada Bureau of Mines and Geology Special Publication 33:162-176.

Jones, C., AND J. Pagels. 1968. Notes on a population of Pipistrellus subflavus in southern Louisiana. Journal of Mammalogy 49:134-139.

Jones, C., AND R.D. SutTKus. 1973. Colony structure and organization of Pipistrellus subflavus in southern Louisiana. Journal of Mammalogy 54:962-968.

JONES, J.K., JR. 1964. Distribution and taxonomy of mammals of Nebraska. Publications of the Museum of Natural History, University of Kansas 16:1-356.

Jones, J.K., JR., D.M. ARmstrong, And C. Jones. 1983. Mammals of the northern Great Plains. University of Nebraska Press, Lincoln.

KunZ, T.H. 1999. Eastern pipistrelle/Pipistrellus subflavus. Pages 114-115 in D.E. Wilson and S. Ruff, editors, The Smithsonian book of North American mammals. Smithsonian Institution Press, Washington, DC.

Kurta, A., And J.A. Teramino. 1994. A novel hibernaculum and noteworthy records of the Indiana bat and eastern pipistrelle (Chiroptera: Vespertilionidae). American Midland Naturalist 132:410-413.

LAVAL, R.K., AND M.L. LAVAL. 1980. Ecological studies and management of Missouri bats with emphasis on cave-dwelling species. Missouri Department of Conservation, Terrestrial Series 8:1-53.

LINDSAY, D.M. 1956. Some bat records from southeastern Indiana. Journal of Mammalogy 37:543-545.

MCNAB, B.K. 1974. The behavior of temperate cave bats in a subtropical environment. Ecology 55:943-958.

Myers, P. 1978. Sexual dimorphism in size of vespertilionid bats. American Naturalist 112:701-711. 
Rabinowitz, A. 1981. Thermal preference of the eastern pipistrelle bat (Pipistrellus subflavus) during hibernation. Journal of the Tennessee Academy Science 56:113-114.

Sandel, J.K., G.R. Benatar, K.M. Burke, C.W. Walker, T.E. LACHer, JR., and R.L. Honeycutt. 2001. Use and selection of winter hibernacula by the eastern pipistrelles (Pipistrellus subflavus) in Texas. Journal of Mammalogy 82:173-178.

SchmidLy, D.J. 1991. The bats of Texas. Texas A\&M University Press, College Station.

SPARKS, D.W., AND J.R. ChOATE. 2000. Distribution, natural history, conservation status, and biogeography of bats in Kansas. Pages 173-228 in J.R. Choate, editor, Reflections of a naturalist: papers honoring Professor Eugene D. Fleharty. Fort Hays Studies, Special Issue 1, Hays, KS.

Speakman, J.R., and D.W. Thomas. 2003. Physiological ecology and energetics of bats. Pages 430-490 in T.H. Kunz and M.B. Fenton, editors, Bat ecology. University of Chicago Press, Chicago, IL.

Speakman, J.R., P.I. Webb, and P.A. Racey. 1991. Effects of disturbance on the energy expenditure of hibernating bats. Journal of Applied Ecology 28:10871104.

Thomas, D.W. 1995. Hibernating bats are sensitive to nontactile human disturbance. Journal of Mammalogy 76:940-946.
Veilleux, J.P., AND S.L. Veilleux. 2004. Intra-annual and interannual fidelity to summer roost areas by female eastern pipistrelles, Pipistrellus subflavus. American Midland Naturalist 152:196-200.

Veilleux, J.P., J.O. Whitaker, JR., and S.L. Veilleux. 2003. Tree-roosting ecology of reproductive female eastern pipistrelles, Pipistrellus subflavus, in Indiana. Journal of Mammalogy 84:1068-1075.

Walker, W.W., J.K. Sandel, R.L. Honeycutt, and C. ADAMS. 1996. Winter utilization of box culverts by vespertilionid bats in southeast Texas. Texas Journal of Science 48:166-168.

Whitaker, J.O., JR. 1998. Life history and roost switching in six summer colonies of eastern pipistrelles in buildings. Journal of Mammalogy 79:651-659.

Whitaker, J.O., Jr., AND L.J. Rissler. 1992a. Seasonal activity of bats at Copperhead Cave. Proceedings of the Indiana Academy of Science 101:127-134.

1992b. Winter activity of bats at a mine entrance in Vermillion County, Indiana. American Midland Naturalist 127:52-59.

Williams, D.F., and J.S. Findley. 1979. Sexual size dimorphism in vespertilionid bats. American Midland Naturalist 102:113-126.

Received 12 September 2007 Accepted 20 March 2008 